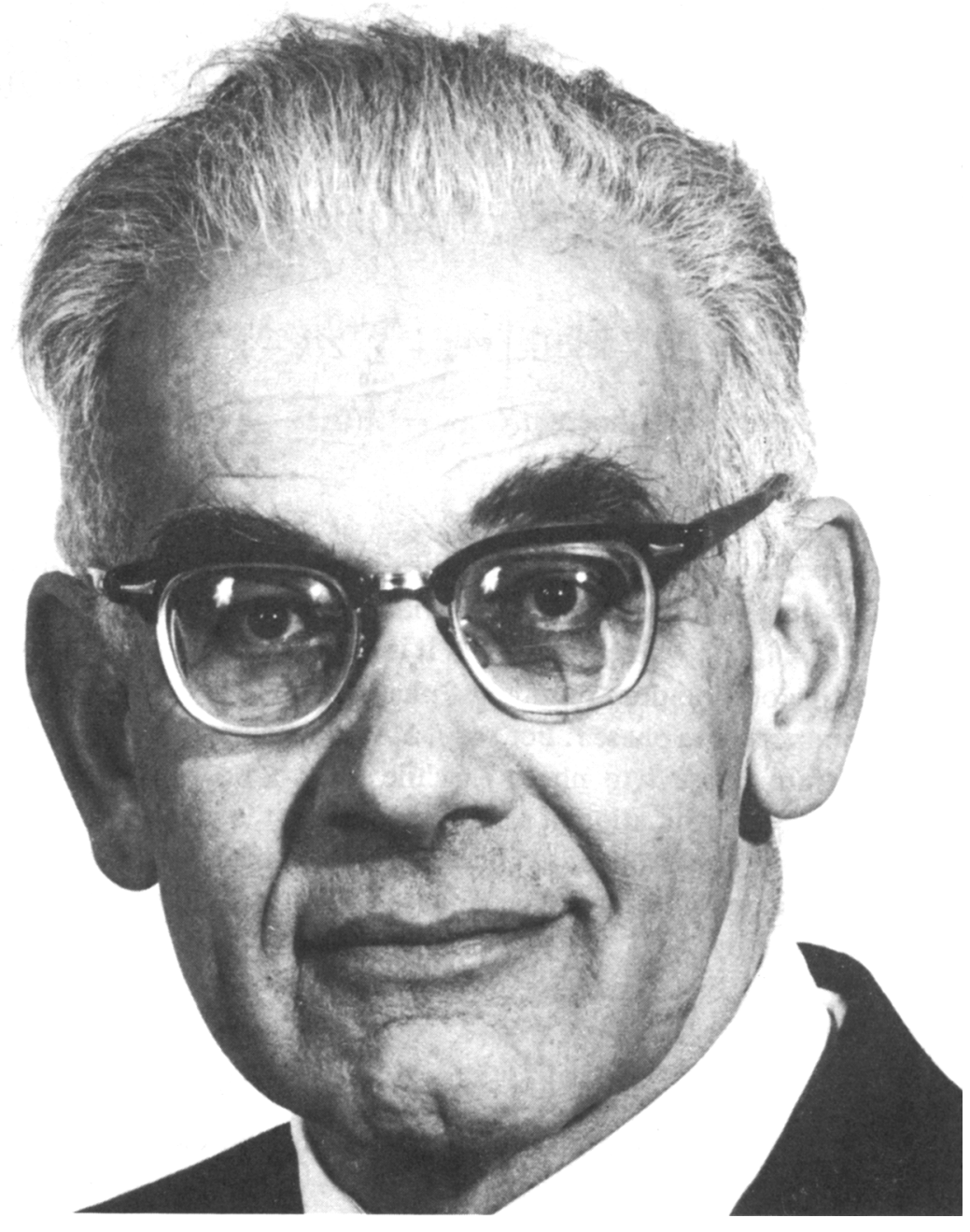

EUGENE LUKACS, 1906-1987 


\section{Obituary: EUGENE LUKACS}

Eugene Lukacs died on 21 December 1987 in Washington, D.C. after several strokes. Well known for his work in characterizations of distributions, stability theory and characteristic functions, and particularly for his now classic Characteristic Functions and several other related monographs, he will be sorely missed by his friends and colleagues all over the world.

Eugene's parents lived in Vienna where his father worked in a bank. When his mother became pregnant, she went to her mother in Szombethely, Hungary where Eugene was born on 14 August 1906. He stayed with his grandparents until he was six weeks old and then was brought to Vienna. He completed his secondary schooling at a Realgymnasium there in 1925. He first decided to study mechanical engineering at the Technical University, but later transferred to the University of Vienna to study mathematics. $\mathrm{He}$ took courses with Professors Hans Hahn, Edward Helly, Walter Meyer, Leopold Vietoris and Wilhelm Wirtinger. It was at the University of Vienna that he met his wife-to-be Elizabeth C. Weisz (Lisl) in 1927. Lisl was a high school senior at the time, with considerable interest in mathematics. Eugene advised her to study mathematics and physics for her university degree. They were married in 1935 . His interest in geometry led him to write his doctoral thesis under Walter Meyer and he obtained his Ph.D. in 1930. Subsequently he took an actuarial degree in 1931.

After teaching for two years at secondary schools in Vienna, Eugene accepted a position in the mathematics division of an insurance company. Edward Helly and Z.W. Birnbaum were amongst his colleagues. He stayed with the insurance company until 1937 and also taught extension courses in mathematics at the Volkshochschule Wien Volksheim. When Germany annexed Austria in 1938 his professional career in Vienna was over and he decided to emigrate to the USA, where he arrived in February 1939.

Upon his arrival in the USA Eugene renewed his acquaintance with Abraham Wald whom he had met in Vienna. Under Wald's influence he became interested in probability and statistics. Wald drew his attention to the vast literature in probability and mathematical statistics which was largely unknown in Central Europe at that time. Wald invited him to attend his, and Hotelling's courses at Columbia University. Thus began his long and fruitful career in statistics during which he wrote five books and over 100 papers. A complete list of his publications up to 1979 appears in Contributions to Probability (Academic Press, 1981), a collection of papers dedicated to him. A supplementary list of his work since then is included at the end of this obituary.

On his arrival in the USA during the aftermath of the great depression, Eugene could not find a suitable position. After teaching high school for a short while, he held teaching positions at several colleges. In 1945 he secured a faculty position at Our Lady of Cincinnati College where he remained until 1953. While he was there, Otto Szász stimulated him to resume working in mathematics. Gradually Eugene became interested in probability theory, and collaborated with Szász on several papers.

While on leave from Our Lady of Cincinnati College, Eugene worked as a mathema- 
tical statistician first at the U.S. Naval Ordinance Test Station in China Lake, California and later at the National Bureau of Standards in Washington, D.C. In 1953 Eugene joined the Office of Naval Research and became head of its Statistics Branch. During his tenure at NBS and ONR he taught at the American University in Washington, D. C. He joined the Catholic University of America in Washington, D.C. in 1955 where he organized and became the Director of the Statistical Laboratory in 1959. Among members of the group were Batschelet, Kawata, Laha, Masuyama and Rohatgi. There were many visitors including Harald Cramér and Paul Lévy, who stayed for one or two semesters. The lecture series also brought many prominent statisticians to the Statistical Laboratory. Eugene remained the director of the Statistical Laboratory until his retirement in 1972. On his retirement the Laboratory folded its operations. He and his remaining colleagues then moved to Bowling Green State University where he remained until 1976. After leaving BGSU, Eugene accepted visiting positions in Vienna and Erlangen until 1978 when he returned to Washington, D.C.

Eugene's primary interest was in the theory of characteristic functions. Until the appearance of the first edition of his celebrated monograph in 1960 the properties of characteristic functions had briefly appeared in the English language only in textbooks such as Cramér's Mathematical Methods of Statistics and Random Variables and Probability Distributions, Gnedenko and Kolmogorov's Limit Distibutions for Sums of Independent Random Variables (English translation), and Loève's Probability Theory. His monograph was the first to present a unified and detailed treatment of the subject, most of the literature of which could only be found in various French and Russian journals. Before long the monograph became indispensable for graduate students and researchers in analytic probability theory. A second edition in 1970 was over twice the size of the first. Characteristic Functions is widely quoted, has been translated into French and Russian, has been and continues to be of great use to students and researchers in analytic probability theory. The second edition was followed by Developments in Characteristic Functions in 1983.

Eugene liked to travel. This led him to spend time teaching or lecturing as visiting professor at the Sorbonne (1961-62, 1965-66), the Swiss Federal Institute, Zürich (1961-62), the Institute of Technology, Vienna (1965-66, 1970, 1975-77), the University of Hull (1971), the University of Sheffield (1974-75), the University of Erlangen (1977-78), the Université Libre de Bruxelles (1961-62) and the University of Athens (1961-62). Short visits took him to Brazil, Oslo, Stockholm, Amsterdam, Moscow, Nice, Belgrade, Helsinki, Petropolis, Rome, Brussels, Tokyo, New Delhi, Sydney, Warsaw, Prague, and many other cities. One of his favorite places was Oberwolfach which he visited often either as a participant or as an organizer of conferences at the Mathematical Research Institute. Another favorite vacation spot was his cottage in the Viennese Woods. He spent part of his summer there practically every year. His hobbies included bird watching, hiking, photography, and coin collecting.

Eugene served the mathematics and statistics community in various capacities. He served as a member of the editorial board of the Annals of Mathematical Statistics (1958-64), as an associate editor of the Annals (1968-70), as an editorial collaborator of the Journal of the American Statistical Association (1951-55, 1961-63), as an editor of 
the Journal of Multivariate Analysis (1970-83), and as a founding editor of the Academic Press Probability and Mathematical Statistics Series (1962-1985). He was a council member of the Institute of Mathematical Statistics (1970-73), served as a member of the AMS Translation Committee, as Chair of the IMS Translations Committee, and as a member of the National Research Council (1969-72).

During his professional career Eugene was the recipient of many honors. In 1976 the Board of trustees at Bowling Green State University honored him with the title of University Professor, the first faculty member at Bowling Green to be so honored. In 1980 he received the Golden Doctoral Diploma of the University of Vienna. He was elected Fellow of IMS in 1957, of ASA in 1969 and of AAAS in 1958. He was elected to a membership of ISI in 1963 and to the Austrian Academy of Science in 1973.

Eugene was a constant source of encouragement to his colleagues and students. He showed a great deal of interest in their work and was always available for consultation. He promptly responded to countless queries that he received from all over the world, mostly on questions concerning characteristic functions.

We shall miss Eugene greatly, not only for his contributions to probability and statistics but also as a colleague, a friend and a human being of integrity.

Bowling Green State University

April 1988

VIJAY K. ROHATGI

\section{Supplementary list of publications of Eugene Lukacs}

1980

Inequalities for Fourier-Stieltjes transforms of functions of bounded variation. In General Inequalities 2 (Proc. 2nd International Conference, Oberwolfach, 1978), Birkhaüser, Basel, 127-133.

\section{1}

Analytical Methods in Probability Theory (with D. Dugué and V. K. Rohatgi). Lecture Notes in Mathematics 861, Springer-Verlag, Berlin.

Construction of characterization theorems. In Analytical Methods in Probability

Theory. Lecture Notes in Mathematics 861, Springer-Verlag, Berlin, 121-127.

Analytic distribution functions. In Statistical Distributions in Scientific Work $\mathbf{4}$, Riedel, Dordrecht, 255-265.

On a modification of the Mellin-Stieltjes transform. C.R. Math. Rep. Acad. Sci. Canada 3, 343-346.

\section{2}

Convergence of sequences of random variables. In Encyclopaedia of Statistical Sciences 2, Wiley, New York, 183-187. 
On some recent advances in the theory of univariate characteristic functions and on the developments which lead to them. In Statistics and Probability, Essays in Honour of C. R. Rao, ed. G. Kallianpur et al., North-Holland, Amsterdam, 465-477.

From Riemannian spaces to characteristic functions: the evolution of a statistician. In The Making of Statisticians, ed. J. Gani, Springer-Verlag, New York, 14-20.

\section{3}

Developments in Characteristic Function Theory. Griffin, London.

Faa di Bruno's formula. In Encyclopedia of Statistical Sciences 3, Wiley, New York, $1-2$.

On the stability of a characterization of the rectangular distribution. Probability and Mathematical Statistics, Uppsala University, 118-128.

\section{4}

On the stability of a characterization of the rectangular distribution. In Statistics and Probability (Visegrád, 1982), Riedel, Dordrecht, 183-190. 